\title{
Resposta dos autores
}

The authors' reply

Marcelo Firpo Porto

Wagner Lopes Soares

Propor uma agenda de pesquisa abrangente e mais completa sobre um tema tão complexo como os agrotóxicos é, certamente, uma tarefa para vários artigos e profissionais com distintas experiências e perspectivas. A oferta feita pela RBSO, de termos um artigo de base com as críticas e as complementações de autores com grande experiência e diversidade de abordagens no campo da saúde pública, possibilita aos profissionais, aos pesquisadores e aos estudiosos comprometidos com o tema uma visão bem mais abrangente e que melhor poderá orientar futuras discussões sobre o assunto.

Os autores agradecem os comentários realizados, reconhecendo que eles ajudam a complementar e a preencher as lacunas do artigo original cujo foco reside no diálogo entre a saúde pública/saúde coletiva e diferentes campos. Dentre estes, destacamos o meio ambiente, a agronomia e, em especial, a

agroecologia, a economia ecológica, além de setores, movimentos sociais e organizações que atuam junto a temas como a segurança química, a segurança e soberania alimentar, a justiça ambiental, a agricultura familiar e a reforma agrária. Tal diálogo, necessário para uma visão abrangente do tema, que aponte para questões como a prevenção e a transição para práticas agrícolas sustentáveis, justas e saudáveis, fez com que o artigo original deixasse de aprofundar diversos temas específicos de interesse da saúde dos trabalhadores e da saúde ambiental.

As contribuições de Neice Müller Xavier Faria trazem a importante experiência do grupo da Universidade Federal de Pelotas que vem se dedicando ao tema da saúde dos trabalhadores rurais e dos agrotóxicos, com a companhia de outros pesquisadores de renome, como Luiz Augusto Facchini e Anaclaudia Fassa. Seu comentário, longo e profícuo, complementa uma agenda de lacunas e necessidades de pesquisas mais específicas baseadas em estudos epidemiológicos e debates envolvendo profissionais da saúde e da área agrícola, pesquisadores e agricultores. Concordamos com os principais argumentos presentes nos sete blocos temáticos que organizam 
uma agenda de pesquisa e ações importantes tanto para diagnósticos mais precisos do problema (consumo, intoxicações agudas, efeitos crônicos, monitoramento biológico da exposição e efeitos), como para as estratégias de formação de profissionais e de proteção dos trabalhadores, incluindo ao final o questionamento sobre o próprio modelo de produção.

O texto apresenta questões de grande relevância, como a revitalização do Receituário Agronômico, pois sua ineficácia e o comércio irregular, incluindo o próprio contrabando de produtos vindos principalmente do Paraguai, constituem-se em importantes fatores de agravamento da exposição entre agricultores e trabalhadores rurais mais vulneráveis. O texto também aborda os limites e os dilemas de se trabalhar com o uso de Equipamentos de Proteção Individual (EPIs) como solução para o controle da exposição, visto que tal recomendação, além de ser apenas paliativa e frequentemente ineficiente, poderia ser entendida como uma incorreta aceitação do próprio agrotóxico enquanto alternativa viável.

Outro ponto, ainda mais complexo, refere-se aos sistemas de informação existentes que poderiam fornecer dados relevantes sobre intoxicações por agrotóxicos. A discrepância entre os dados do Sinan, do Sinitox e do Censo Agropecuário do IBGE aponta, além da grande subnotificação nos sistemas de saúde existentes, para a necessidade de pesquisas que revelem, com mais acurácia, a incidência de trabalhadores e pessoas intoxicadas com agrotóxicos. Porém, para além dessa necessidade, deve ser ressaltada a importância dos dados e estimativas já existentes no Brasil e em outros países, os quais apontam, ainda que com várias incertezas, para a enorme gravidade do problema. Isso deveria ser suficiente, seguindo uma tendência internacional em diversos países, para a implementação de políticas públicas que reduzissem e eliminassem a massiva exposição a agrotóxicos de trabalhadores, moradores e consumidores. A falta de priorização deste tema no Brasil se deve basicamente aos fortes interesses econômicos em jogo e à ainda relativamente baixa mobilização da sociedade sobre o tema, o que está mudando, conforme comentaremos mais à frente.

Embora concordemos com a dificuldade de serem estabelecidos nexos causais e epidemiológicos entre agrotóxicos e problemas como câncer, hepatopatias, neuropatias, distúrbios hormonais e outros, acreditamos que as evidências já existentes, do ponto de vista precaucionário e de defesa da vida, são suficientes para deflagrar campanhas e políticas públicas voltadas à prevenção dos riscos e à promoção da saúde, por exemplo, através do incentivo à produção e ao consumo de alimentos saudáveis. O argumento adotado por representantes da indústria e do agronegócio de que somente após a realização de estudos de natureza bastante complexa (como a exposição a múltiplos agentes químicos) deveriam ser tomadas medidas mais efetivas para um combate mais efetivo ao uso e à exposição de agrotóxicos, tem servido como estratégia de defesa para a manutenção ou mesmo expansão do atual modelo de produção e consumo. Portanto, a necessidade de mais estudos não deveria ser um empecilho para uma mobilização mais intensa em torno de políticas mais efetivas de transição para práticas agrícolas sustentáveis, justas e saudáveis.

Uma das propostas mais interessantes apresentada por Neice Faria, dada sua viabilidade no curto prazo e seu relativo baixo custo, é a criação de um portal na internet com informações toxicológicas gratuitas, abordando efeitos agudos e crônicos, bem como orientações de manejo clínico para cada tipo químico de agrotóxicos usado no país, baseado na experiência de outros países, como a Extoxnet, criada por uma rede de universidades norte americanas. Iniciativa semelhante poderia ser desenvolvida num relativo curto prazo, com o apoio de instituições como o Ministério da Saúde e a Agência Nacional de Vigilância Sanitária (Anvisa), que já possuem base semelhante e poderiam redirecioná-la com a finalidade de dar um melhor suporte aos profissionais de saúde e à população em geral.

Uma questão não mencionada diretamente por Neice Faria, mas que consideramos estratégica para simultaneamente diagnosticar o problema e sensibilizar a sociedade e o poder público, refere-se à contribuição dos economistas no debate, no sentido de aprofundar as avaliações econômicas desses produtos, levando em conta os impactos econômicos para a sociedade e não apenas os seus benefícios privados imediatistas. Afinal de contas, as "vantagens" econômicas do uso dos agrotóxicos ocorrem em grande parte pelo fato de serem fortemente subsidiados pela isenção de impostos e também porque os impactos à saúde e ao meio ambiente são pagos pela sociedade como um todo. Além do sofrimento dos trabalhadores e moradores expostos e seus familiares, é basicamente o SUS e a Previdência Social que arcam com os custos dos problemas de saúde provocados pelos agrotóxicos, e não os fabricantes e usuários dos agrotóxicos. Essa grande injustiça, que os economistas denominam de "externalidade negativa", reforça a opção pelo agrotóxico por parte de inúmeros agricultores. Estudos de avaliação econômica deste tipo para todo território nacional, mesmo de forma parcial, incluindo apenas algumas externalidades, ajudaria a desmascarar de vez o discurso em defesa da segurança alimentar baseado na relação entre uso de agrotóxicos, abastecimento e combate à fome, o qual vem servindo para legitimar esse modelo de agricultura, muitas vezes em consonância com a política agrícola 
oficial. A produção de números cientificamente robustos acerca desses impactos sem dúvida colocaria em xeque o incentivo e a proteção do governo a uma indústria que impõe aos setores da saúde, da previdência social, do meio ambiente e à sociedade como um todo enormes prejuízos, os quais, na maioria das vezes, encontram-se invisíveis nas estatísticas oficiais, principalmente no que diz respeito à saúde das populações. Existe um déficit oculto da contribuição ao PIB pelo agronegócio que precisa ser desvelado para que a noção de desenvolvimento incorpore efetivamente sua dimensão humana e ambiental.

O texto de Jorge Machado, histórico militante da saúde dos trabalhadores e ambiental na SaúdeColetiva, indica adequadamente que "uma agenda de pesquisa requer, ao mesmo tempo, um programa de restrição do uso dos agrotóxicos no Brasil: a agenda do uso restrito" (p. 40) e, em seguida, enuncia algumas propostas. Como em todo assunto complexo e que envolve simultaneamente questões políticas, econômicas, ambientais e de saúde, o ponto aqui se refere a como, dialeticamente, dosar as energias em torno da restrição ao uso e, ao mesmo tempo, enfrentar de forma mais ousada o próprio modelo de produção. Esta última opção envolve a busca de alternativas que caminhem para o próprio fim dos agrotóxicos, implicando no fim das monoculturas e da concentração fundiária tal como hoje continuam a se difundir, ou seja, assumir uma agenda mais profunda de transição agroecológica, de reforma agrária e de mudança da lógica do comércio internacional injusto e insustentável que mantém o modelo hegemônico atual. Nesse sentido, seguindo sua vocação histórica, entendemos que a Saúde Pública deve se posicionar como um importante aliado deste processo de proteção da vida.

Concordamos totalmente com Jorge Machado quando ele afirma que vivemos um momento especial de:

reflexão, aprofundamento e ação em relação ao uso dos agrotóxicos no Brasil, no sentido do desvelamento do seu real impacto na saúde pública, do grau de intoxicação dos trabalhadores rurais e de contaminação, via alimentos, de toda a população brasileira e de como pode ser revertido esse processo. (p. 41)

As diversas propostas de governança, ações de vigilância e financiamento fundamentam uma base sólida para a atuação do Ministério da Saúde e do SUS, porém elas serão tanto mais efetivas quanto maior for a capacidade de mobilização da sociedade em torno do tema.

Uma importante prova disso tem sido a mobilização no país desencadeada pela Campanha Nacional Contra o Uso de Agrotóxicos, iniciativa coordenada por diversas entidades de movimentos sociais, instituições e organizações acadêmicas, com o apoio de inúmeras entidades e grupos de pesquisa pelo país. O uso de ferramentas de comunicação na campanha, como o filme $O$ Veneno está na mesa (2011), do cineasta Silvio Tendler, e o livro Agrotóxicos no Brasil - um guia para ação em defesa da vida, de autoria de Flavia Londres (2011) e fruto de uma iniciativa conjunta da Articulação Nacional de Agroecologia (ANA) e da Rede Brasileira de Justiça Ambiental (RBJA), além da organização de comitês estaduais e inúmeros debates em diversas cidades do país, estão por detrás da enorme repercussão do que pode ser considerada a principal campanha de discussão pública já ocorrida no país.

Paralelamente, devem ser citados outros processos em curso que revelam o amadurecimento da sociedade brasileira sobre o tema. Por exemplo, os debates públicos dos resultados de dois dos grupos de pesquisa mais engajados e importantes do país. O primeiro é o da Universidade Federal de Mato Grosso, sob a liderança do professor Vanderlei Pignati e em cooperação com a Fiocruz, através da liderança do pesquisador e toxicologista Josino Moreira. Os resultados das pesquisas, em especial a contaminação de leite materno, apontam para a gravidade da contaminação no estado de Mato Grosso e foi veiculado pelos principais meios de comunicação do país (WOLFART; JUNGES, 2011), o que gerou inclusive ameaças aos pesquisadores envolvidos. O outro grupo de pesquisa, do Núcleo Tramas da Universidade do Ceará, coordenado pela professora Raquel Rigotto, é possivelmente o exemplo do grupo mais avançado sobre o tema dos agrotóxicos na prática de um ciência engajada em prol da justiça ambiental no país. Os estudos sobre a contaminação por agrotóxicos na fruticultura de exportação no Ceará revelam, além da gravidade epidemiológica e ambiental, o nível de violência dos conflitos agrários no Brasil, exemplificado no assassinato do agricultor Zé Maria do Tomé, que passou os últimos anos de vida lutando contra problemas como expropriação fundiária, moradias precárias e abuso de agrotóxicos na região da Chapada do Apodi. Recentemente, o grupo liderado por Raquel Rigotto publicou o livro Agrotóxicos, trabalho e saúde: vulnerabilidade e resistência no contexto da modernização agrícola no Baixo Jaguaribe-Ceará (RIGOTTO, 2011), fruto de quatro anos de pesquisa. O livro contribui para a compreensão das inter-relações da expansão do agronegócio com o trabalho, o ambiente, a saúde e o modo de vida dos camponeses.

Outro importante fato no ano de 2011 foi a criação da Comissão sobre Agrotóxicos no Congresso Nacional, que mobilizou diversas audiências públicas e gerou recomendações e projetos de lei, muitos dos quais devem ter grande dificuldade para seguirem em frente diante da força da bancada ruralista pró-agrotóxicos. Porém, os debates serviram para tornar mais evidentes inúmeros absurdos, como a decisão tomada em fins dos 
anos 1990 por secretários estaduais de fazenda que considera os agrotóxicos um insumo agrícola equivalente, por exemplo, a tratores e por isso devem receber uma grande isenção de impostos em todo o país. Ao mesmo tempo, órgãos como a Anvisa cobram um valor irrisório para avaliarem novos agrotóxicos no mercado, inexistindo no país um fundo especial de apoio a pesquisas e atenção às vítimas de contaminação que batem às portas do SUS. A proposta de criação de um fundo de financiamento de investigação e de atividades de vigilância em saúde para redução do uso dos agrotóxicos no Brasil também está presente no texto de Jorge Machado. Cabe também mencionar que se encontra em gestação, coordenada pelo Ministério de Meio Ambiente, uma Política Nacional de Agroecologia, que poderá desempenhar um papel estratégico nos próximos anos para a mudança do atual modelo de produção agrícola.

Por fim, o texto de Andrea Waichman apresenta as contradições presentes para se elaborar e implementar políticas públicas que envolvam todos os interessados. Como reconhece a autora, a "indústria agroquímica e o setor agrícola parecem desprezar ou ignorar os efeitos dessa estratégia defensiva, que são perversos” (p. 42). Concordamos com a pesquisadora quanto a ser necessário o estímulo ao desenvolvimento de pesquisas independentes e, para isso, é importante superar os entraves para a realização da avaliação de riscos no Brasil, incluindo a escassez ou mesmo ausência de dados toxicológicos e ecotoxicológicos gerados sob condições locais e reais de uso, além de dados epidemiológicos.

Uma diferenciação que temos ao tom de certos comentários da autora se refere à forma como compreendemos as diferentes responsabilidades sobre o triste fato do país ter se tornado o principal consumidor de agrotóxicos no mundo. Certamente, os agricultores e a sociedade de forma mais ampla possuem parcela de responsabilidade, mas consideramos incomparavelmente maior a dos produtores de agrotóxicos - os "criadores do risco" - e os grandes proprietários de estabelecimentos rurais que consomem a maior parte dos agrotóxicos, inclusive com mais recursos para orientações técnicas e o uso de receituário agronômico. Ora, os pequenos produtores foram e permanecem vítimas da falta de opções diante de créditos agrícolas que, durante anos, os obrigaram a assumir os agrotóxicos dentro do "pacote tecnológico" no âmbito da revolução verde disseminada por organismos internacionais e por diversos governos. Outro aspecto fundamental se refere à falta de informações que contribui para a falta de mobilização da sociedade: infelizmente alimentos contaminados não possuem características físicas ou odores que permitam o seu reconhecimento imediato, e os efeitos crônicos da contaminação se dão de forma lenta e insidiosa, contribuindo para a invisibilidade do problema.

Portanto, embora concordemos que o modelo agrícola como um todo se encontra fortemente dependente do consumo de agrotóxicos, não consideramos justo tornar equivalentes a responsabilidade dos grandes e dos pequenos agricultores, visto que a concentração fundiária e as monoculturas são, por definição, dependentes dos agrotóxicos e um traço marcante da expansão do agronegócio no país. Também não devemos nos esquecer que a implantação da "revolução verde" no Brasil e os incentivos à indústria do agrotóxicos ocorreram em plena ditadura militar, portanto em ambiente pouco democrático e nada propício para se levantar publicamente questões ambientais e de saúde, embora o livro de Rachel Carson, Primavera silenciosa, já tivesse sido publicado desde 1962 nos EUA.

Recebido: 02/12/2011

Aprovado: 27/04/2012

modernização agrícola no Baixo Jaguaribe-Ceará. Fortaleza: Universidade Federal do Ceará, 2011.

WOLFART, G.; JUNGES, M. Não existe uso seguro de agrotóxicos. Revista IHU On-line, v. 11, n. 368, 4 jul. 2011. [Entrevista com Wanderlei Pignati]. Disponível em: <http://www.ihuonline. unisinos.br/index.php?option $=$ com_content\&view $=$ article\&id $=3975 \&$ secao $=368>$. Acesso em: 23 mar. 2012. 